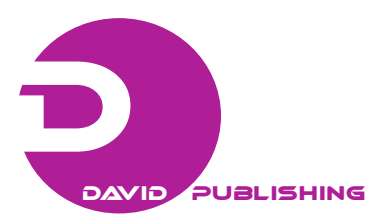

\title{
Durability of Stress Ribbon Bridge Checked during Loading Test
}

\author{
Bogusław Markocki ${ }^{1}$ and Marek Salamak ${ }^{2}$ \\ 1. Royal Haskoning DHV Ltd., Warsaw 01-793, Poland \\ 2. Department of Mechanics and Bridges, Silesian University of Technology, Gliwice 44-100, Poland
}

\begin{abstract}
Stress ribbon bridges have many advantages and became recently more popular mostly because of their versatile form, slender decks giving a light aesthetic impression and durability assured by post tensioned concrete. The paper presents the first in Poland stress Ribbon Bridge constructed last year. A static and dynamic analyse of the model is presented as well as construction solutions which were used to achieve the highest durability. The bridge was checked during static and dynamic load test. The results of this prove test were compared with results obtained from examination and study of other different bridge structures. It confirmed that the bridge has good dynamic resistance and greater stiffness than assumed in the design.
\end{abstract}

Key words: Footbridges, stress ribbon bridges, loading test, bridge dynamic.

\section{Introduction}

In 2009 as a result of a sudden flood in Polish Carpathian Mountains, a small bridge shortening significantly the way and situated over the torrent river at the subdivisions was destroyed. Local authorities were forced to hold a tender for the new foot and road bridge which was supposed to be as well cheap and fast to build and as durable and easy to use.

The winner of bidding was a contractor company IMB Podbeskidzie Ltd., which in cooperation with DHV Poland Ltd., has made the most attractive economically and qualitatively offers for prestressed concrete ribbon bridge which was new for Polish conditions (Fig. 1). The proposed construction of bridge has gained approval of investors due to its characteristics mentioned in list as follow:

(1) Aesthetics: The bridge is designed as "quiet" and slender in shape, harmonizing with natural mountainous landscape;

Corresponding author: Boguslaw Markocki, M.Sc., research fields: bridge engineering, structure engineering, structure dynamic, bridge load tests, footbridges, geotechnical and deep foundation analysis. E-mail: markocki.info@gmail.com.
(2) Low price: The design uses an innovative solution which allows lowering the price (pre-stressed concrete ribbon structure, execution without expensive shuttering, foundation on Cutter Soil Mixing Barets);

(3) Durability: The use of modern and high strength materials allows the utilization of the bridge for more than 100 years (a high quality compressed concrete $\mathrm{C}$ $50 / 60$, stressing tendons and anchors secured with concrete);

(4) Fast implementation: The design and the construction of bridge took seven months which can be shortened by better team coordination;

(5) Features: Besides foot crossing $\left(4 \mathrm{kN} / \mathrm{m}^{2}\right)$ it was supposed to enable driving vehicles up to $15 \mathrm{t}$ when the road was $2.75 \mathrm{~m}$ wide;

(6) Moreover, because of local hydrological and ecological conditions it was supposed to have the span at least $70 \mathrm{~m}$ long matching the mountainous landscape.

\section{Structure Description}

The foundation of the bridge was made in CSM (cutter soil mixing) technology as cement soil barrettes. 


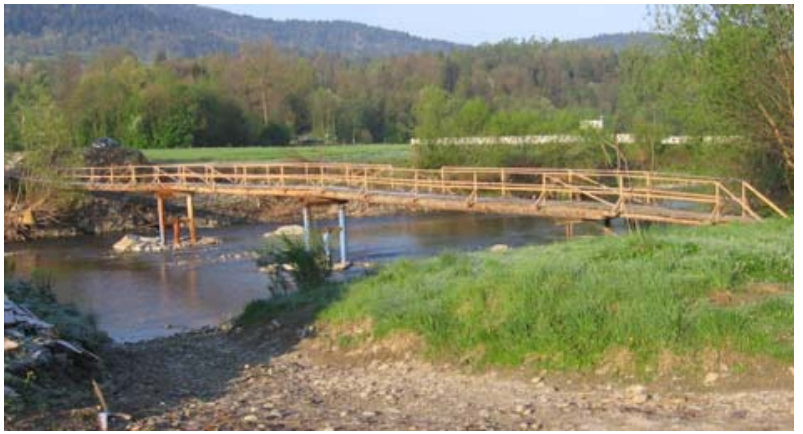

(a)

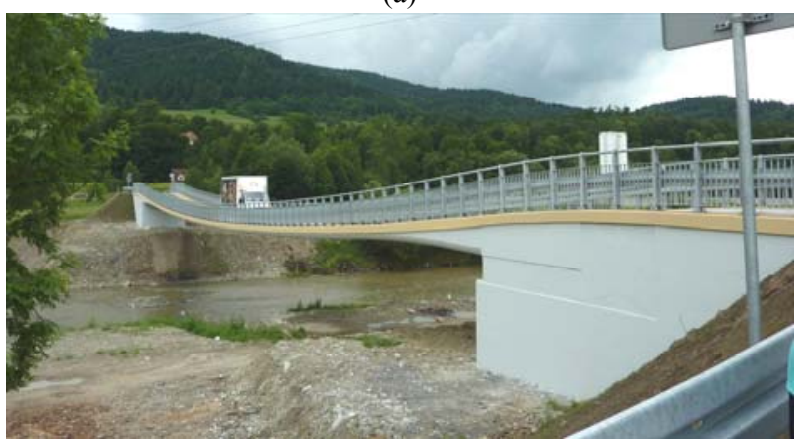

(b)

Fig. 1 (a) Damaged in a flood bridge; (b) a view of the new structure.

This solution improved radically mechanical properties of existing soil base. Together with cement mortar soil makes substance which is homogeneous and guarantees compression strength greater than 12.5 MPa. Such formed foundation blocks work both with the base and side surfaces which increase the resistance of friction on the side surfaces and the resistance pressure at the front of the foundation. In order to ensure its stability 12 permanent anchors were used with a length of $18.5 \mathrm{~m}$ (Fig. 2).

Ribbon Bridge with a length of $91.4 \mathrm{~m}$ and the distance between supports $71.4 \mathrm{~m}$ is $5.54 \mathrm{~m}$ wide with a total structural height $47 \mathrm{~m}$ (Fig. 2). It was made of concrete $\mathrm{C} 50 / 60$ stressed by cables consisting of 12 and 19 strands. Precast elements of the bridge of the

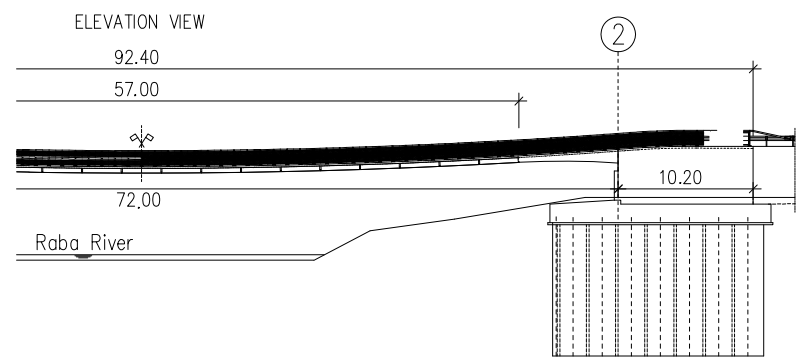

Fig. 2 Longitudinal and transverse section (unit: $\mathrm{m}$ ). length about $3 \mathrm{~m}$ were suspended for eight tendons anchored in the concrete solid abutments. The edge segments $7.5 \mathrm{~m}$ long on the both sides were made on stationary scaffoldings.

While designing the bridge a special attention was put on the durability in terms of large, cyclic concentrated loads from vehicles. Because of that the construction had to meet higher standard requirements than footbridges loaded only with crowds of pedestrians. Construction solutions $[1,2]$ which were used to achieve the highest durability are:

(1) Reduced stress of the entire length of the deck while allowing a small tensile stresses in the concrete. The only exceptions are the joints of the in-situ and precast parts, where soft reinforcement was increased to a level that cracks did not exceed $0.1 \mathrm{~mm}$;

(2) Using steel pipes as shields of bearing tendons, which besides protecting the cables against damage during assembly of precast segments are an additional reinforcement of tensile and shear forces in the bridge providing additional protection against corrosion;

(3) Including all the tendons into the system carrying live and thermal loads. Ribbon bridge, after completion works as the composite structure. The share of reinforcing and stressing steel in total cross-section of a concrete system is significant and very effectively increases the stiffness of the whole structure.

The author assembled prefabricated suspension system that allows assembling into cables and carrying to the destination (Fig. 3). Also concreting supporting sections was designed in a way that formworks could be hung on the load-bearing cables. The solutions allowed to reduce costs significantly

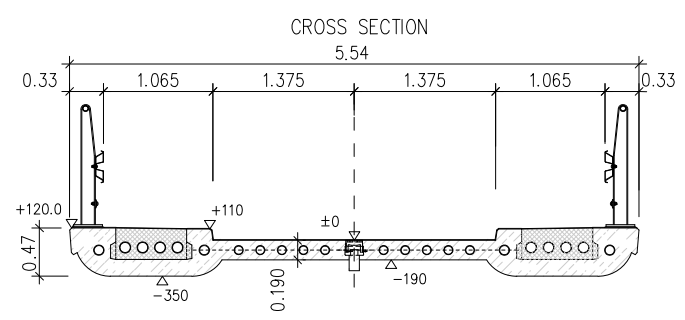



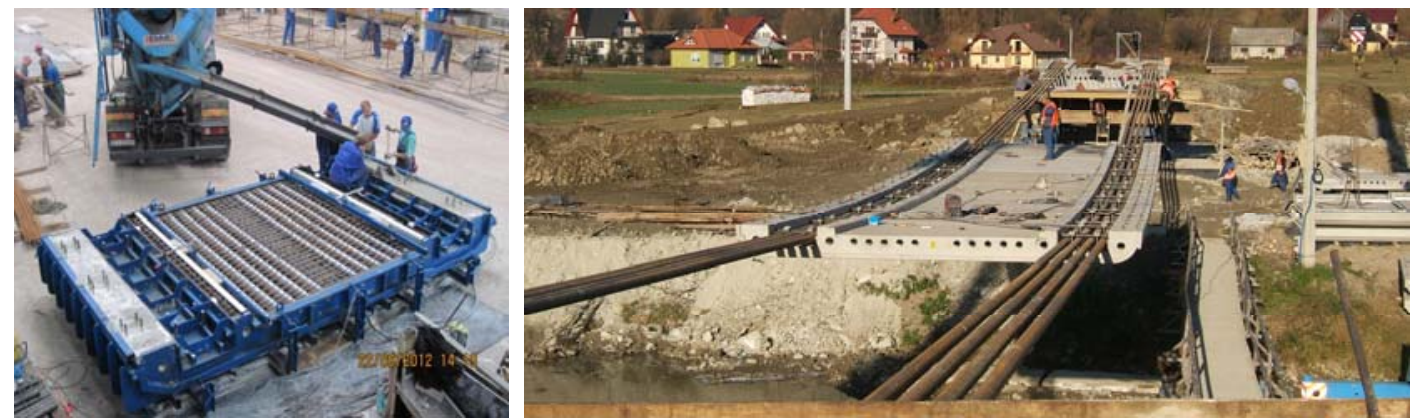

Fig. 3 Concreting and assembly of precast bridge elements.

accelerate the time of its implementation. After installation of precast segments closing support sections were made in-situ. Stressing was started after seven days of concreting. Stressing works required great precision, because the forces in the tendons were affecting directly the deformations of the structure. Therefore, the stressing force was applied in three stages, and the work was carried out with two jacks with two symmetrical tension cables on the one side of the bridge. The last stage was concreting the bays in the abutments in the location of tendon heads and technological breaks in the abutment and making corrosion protection as well as assembling equipment.

Static analysis of the bridge included geometrically and material changeable system which was a result of the accepted erection stages and rheological processes of the concrete and stressing steel. Calculations were done using the bridge nonlinear analysis taking into account the stages of the bridge assembly. Each next step of calculations took into account the deformations of the preceding stages. Control measurements carried out during the construction of the bridge confirmed the very good compatibility of predicted forces in cables and deformations of the bridge elements in different stages of the construction (Table 1) [3].

Dynamic calculations were done to determine the risks associated with the sensitivity of the dynamic structure and pedestrian comfort. The deep analysis of the numerical model was held using numerical solving equations of motion. The bridge was loaded with the few schemes of load simulating different cases of pedestrian load, using the universal model (1) elaborated by Seiler and Huttner [4] which is shown in Figs. 4 and 5.

$$
F(t)=\left\{\begin{array}{l}
G \cdot\left[1+s \cdot \cos \left(2 \cdot \pi \cdot f_{G} \cdot t\right)\right] \leftarrow-\frac{t_{c}}{2}<t \leq \frac{t_{c}}{2} \\
0 \leftarrow \frac{t_{c}}{2}<t \leq T-\frac{t_{c}}{2}
\end{array}\right.
$$

where,

$G$ : load of a pedestrian or a group of pedestrians;

$s$ : dynamic pulse rate;

$f_{G}$ : analyzes frequency of oscillations;

$T$ : period of vibration;

$t_{c}$ : time of contact of the foot with the ground.

Besides the case of crossing vehicle was simulated alternatively. Firstly, as one dimensioned oscillator loaded by timeline function, and next as continuous vehicle cross with taking into account variable vehicle position together with deck deflection. Vehicle speeds $(10,20,30 \mathrm{~km} / \mathrm{h})$ were the same as excitations used later during the load test.

Basic natural frequencies and modes are shown in (Fig. 6), as far as vertical vibrations are concerned there is only one mode with frequency $1.93 \mathrm{~Hz}$ in the range of critical values (1.6-2.4 Hz) [3]. The following two can caused some doubts only in the case of too small damping. As far as lateral vibrations are concerned the first not shown here mode has frequency $4.67 \mathrm{~Hz}$ and is completely beyond the critical range $(0.7-1.3 \mathrm{~Hz})$. Therefore in theoretical and experimental analysis it was decided to focus on the three modes of the following frequencies 1.93, 2.62 and $3.09 \mathrm{~Hz}$. 
Table 1 Superstructure displacements in each stage during execution (middle of the span).

\begin{tabular}{llll}
\hline \multirow{2}{*}{ No. } & Stage & \multicolumn{2}{c}{ Superstructure sag $(\mathrm{mm})$} \\
\cline { 3 - 4 } & & Calculated value & Measured value \\
\hline 1 & Assembling of bearing cables & 500 & 500 \\
2 & Assembling seven prefabricates & 2,195 & 2,187 \\
3 & Pulling bearing cables with seven prefabricates & 1,350 & 1,350 \\
4 & Assembling 12 prefabricates & 2,045 & 2,030 \\
5 & Pulling bearing cables with 12 prefabricates & 1,115 & 1,025 \\
6 & Concreting holes in prefabricate and deck section & 1,425 & 1,427 \\
7 & Pre-stressing superstructure & 1,400 & 1,395 \\
\hline
\end{tabular}
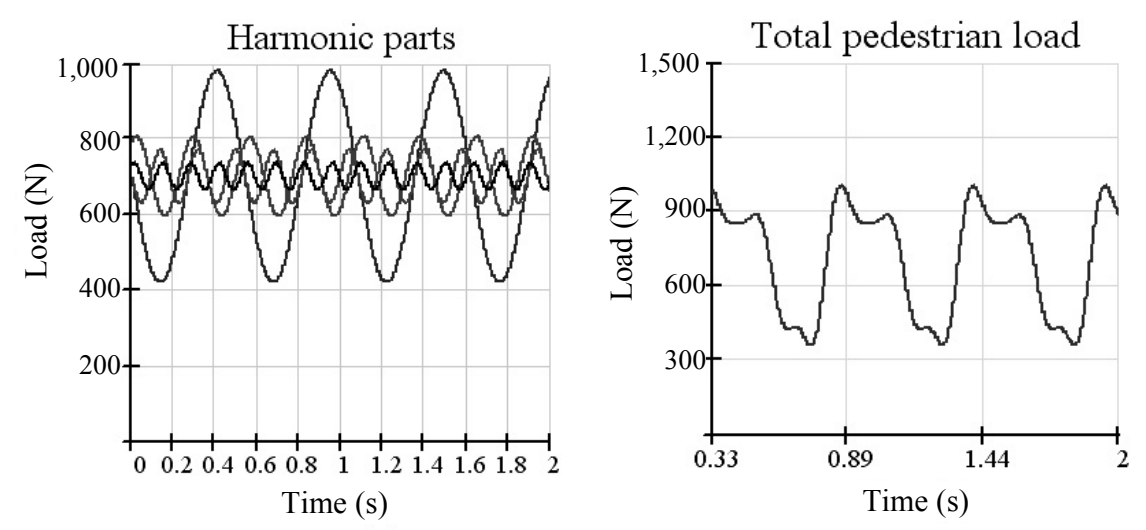

Fig. 4 Model of pedestrian load—marching [4].
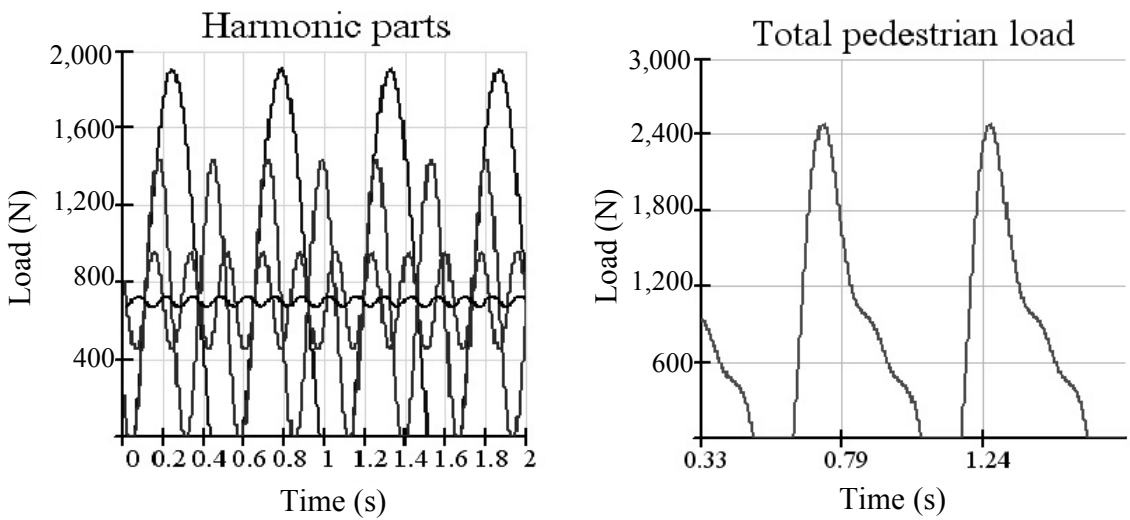

Fig. 5 Model of pedestrian load-jumping [4].

\section{Load Test}

The program of load test was more extensive then in case of typical road bridge. A number of situations were arranged that could occur during the use of the footbridge. Dynamic action of a crowd was simulated by a group of a dozen or so people. Columns of pedestrians marching rhythmically, people running and crossing by disorderly groups of various numbers of people were the cases investigated. Each of these was done twice in each direction. A single person also rhythmically walked across the footbridge both ways. Malicious actions were performed by rhythmical jumping of several persons in spots of the structure indicated as sensitive. And finally, a dynamic response to a special vehicle (loaded fire truck with weight $151 \mathrm{kN}$ ) driving across the bridge was studied.

Measurements were made with the set consisted of the following main components: portable computer, 16-bit measurement card with conditioner and a set of 


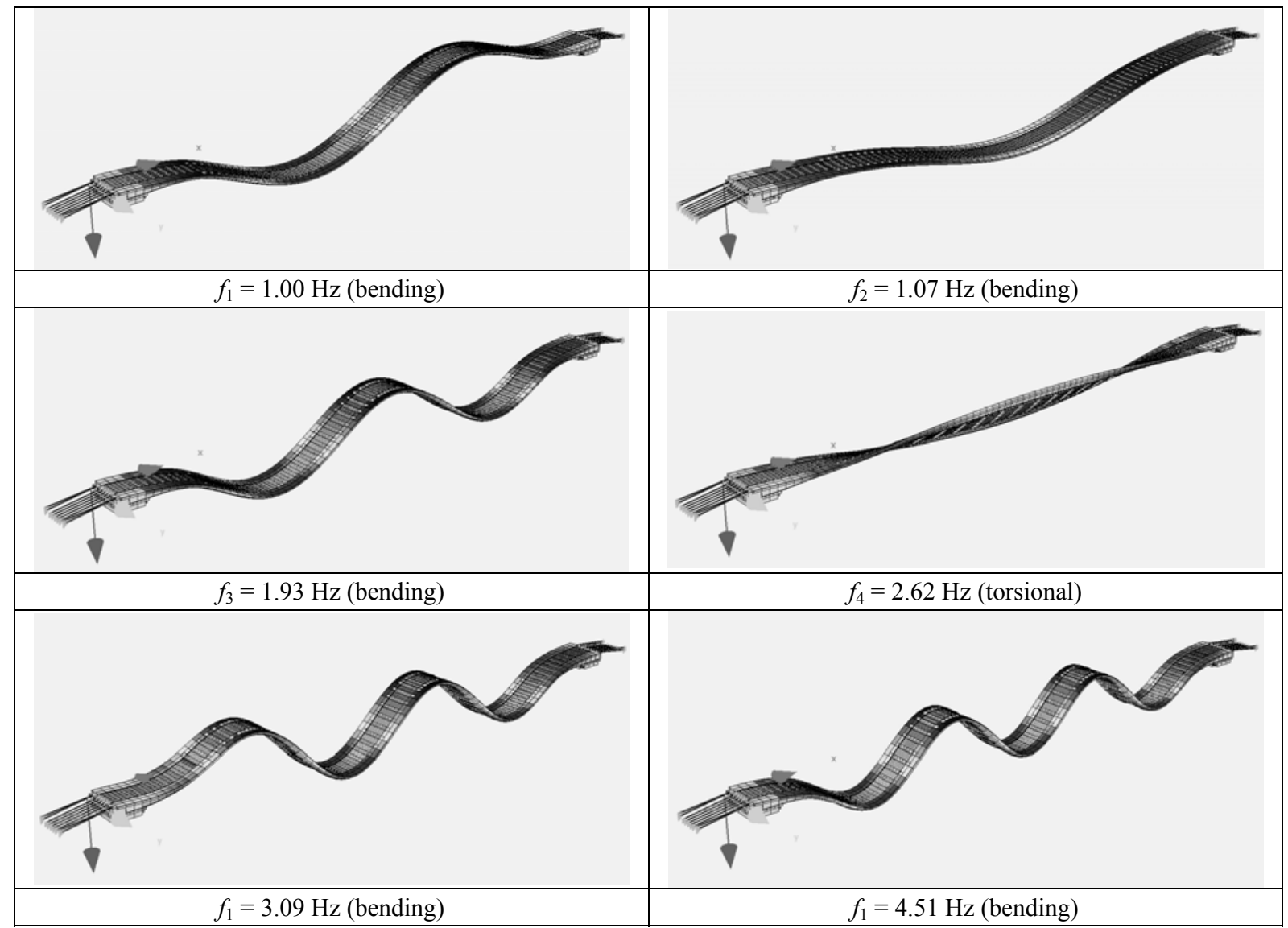

Fig. 6 Basic natural frequencies and modes.

displacement sensors and accelerometers (Fig. 7). The set enables simultaneous recording of results on 16 channels at a rate of $100 \mathrm{~Hz}$. The analysis of the recorded results was aimed mainly on determining the principal dynamic features of these structures, such as dynamic resistance and probability of resonant phenomenon. This was accomplished by way of identifying system parameters, such as natural frequency, form of free vibration and degree of damping expressed in the form of LDD (logarithmic damping decrement). Table 1 presents basic results compared to other five footbridges tested by our team recently [5]. Structural schemes of these bridges are shown in Fig. 7.

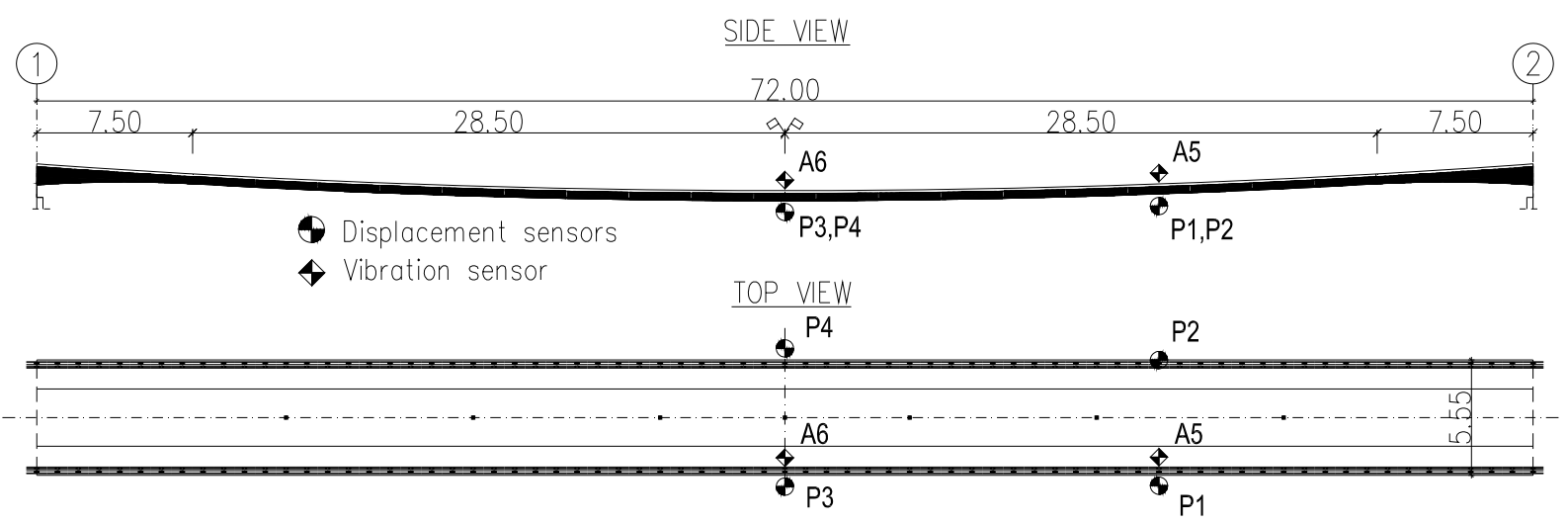

Fig. 7 Location of measuring points. 
Deflection in static test caused by the vehicle standing in the middle of the span was $23.5 \mathrm{~mm}$ with non-significant displacement of cable anchorages (up to $0.1 \mathrm{~mm}$ ). It stated $45 \%$ of the theoretical deflection obtained in the initial model which assumed larger elasticity of anchorage blocks (even $1 \mathrm{~mm}$ ). After the model revision compatibility was on the level of $92 \%$.

It was possible to identify first four modes of vibrations (Table 2) which natural frequencies were close to the theoretical (Fig. 6). The author's team has tested many different bridges, also for pedestrians [6-8]. Measured damping values are small comparing to other tested footbridges (Fig. 8) described in Ref. [5] but similar to those written in bibliography $[1,3,8,9]$. Damping nonlinearity and amplitude dependence is very distinctive. The value of damping decreases together with decreasing amplitudes.

The vehicle crossings with different speeds allowed to determine a DAF (dynamic amplification factor), which is defined as a relation of maximal deflection obtained in passing with the given speed to deflection measured during quasi-static passing with speed 5 $\mathrm{km} / \mathrm{h}$. DAF values are between 1.01 and 1.07 and are greater than standard dynamic coefficient which is equal 1.0. Selected results (deflections and accelerations) caused by pedestrians are listed in Table 3.

\section{Conclusions}

Constructing the first stress ribbon bridge in Poland gave Polish bridge engineering society valuable

Table 2 Results of a load test in comparison to results from other tested footbridges.

\begin{tabular}{|c|c|c|c|c|c|c|c|c|c|c|c|}
\hline \multirow{3}{*}{ Footbridge } & \multirow{2}{*}{\multicolumn{4}{|c|}{$\begin{array}{l}\text { Frequency } f(\mathrm{~Hz}) \\
\text { vibration modes }\end{array}$}} & \multirow{2}{*}{\multicolumn{4}{|c|}{$\begin{array}{l}\text { Damping } \zeta(\%) \\
\text { vibration modes }\end{array}$}} & \multirow{3}{*}{$\begin{array}{l}\text { Span } \\
\text { length } \\
(\mathrm{m})\end{array}$} & \multicolumn{2}{|c|}{ Stiffness } \\
\hline & & & & & & & & & & Deck EI & Structure \\
\hline & 1 & 2 & 3 & 4 & 1 & 2 & 3 & 4 & & $\left(\mathrm{MN} \cdot \mathrm{m}^{2}\right)$ & $(\mathrm{kN} / \mathrm{mm})$ \\
\hline Chorzów & 1.62 & 2.07 & 3.19 & 3.38 & 1.34 & 1.67 & 1.46 & 1.26 & 46 & 510 & 0.83 \\
\hline Ruda & 1.02 & 2.05 & 2.45 & 3.23 & 0.70 & 4.69 & 1.78 & 0.54 & 55 & 2,330 & 3.23 \\
\hline Uniwersytecka & 1.17 & 2.53 & 2.77 & 3.17 & 2.88 & 2.80 & 2.50 & 2.04 & 63 & 4,890 & 2.33 \\
\hline Kielce & 2.06 & 2.26 & 2.48 & 3.31 & 2.16 & 2.91 & 2.07 & 1.70 & 37 & 420 & 0.65 \\
\hline Murckowska & 1.74 & 3.24 & 3.92 & 4.21 & 0.52 & 0.80 & 1.86 & 2.11 & 41 & 1,500 & 2.17 \\
\hline Lubien & 1.08 & 1.20 & 1.96 & 2.60 & 0.67 & 1.00 & 0.35 & 0.75 & 71 & 355 & 3.57 \\
\hline
\end{tabular}
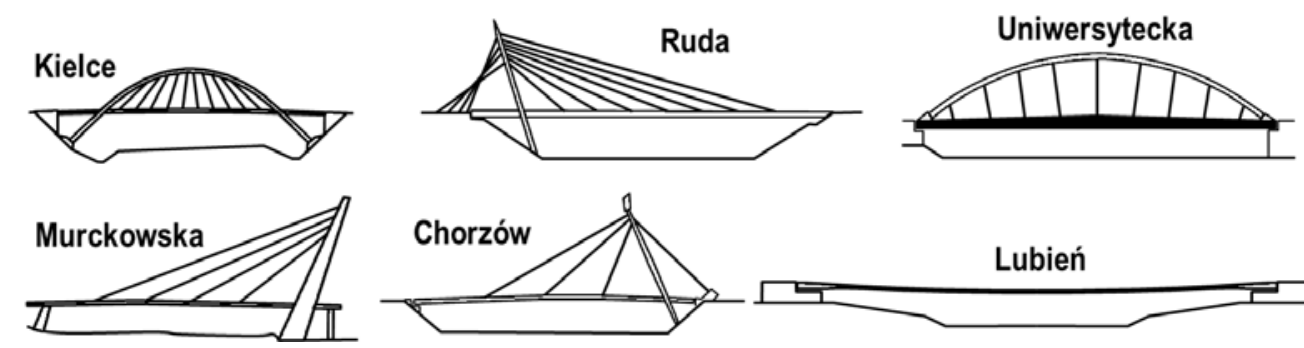

Lubień

Fig. 8 Structural schemes of footbridges taken to comparison.

Table 3 Measured deflections and accelerations caused by selected excitations.

\begin{tabular}{lll}
\hline Type of excitation & Deflection $(\mathrm{mm})$ & Acceleration $\left(\mathrm{m} / \mathrm{s}^{2}\right)$ \\
\hline March of 1 persons synchronized with 3rd mode & 0.40 & 0.01 \\
March of 15 persons non-synchronized & 2.09 & 0.03 \\
Run of 1 person synchronized with 4th mode & 0.44 & 0.07 \\
Run of 15 persons synchronized with 4th mode & 4.07 & 0.49 \\
Jumps of 15 persons synchronized with 3th mode & 1.85 & 0.30 \\
Jumps of 15 persons synchronized with 4th mode & 9.71 & 1.75 \\
\hline
\end{tabular}




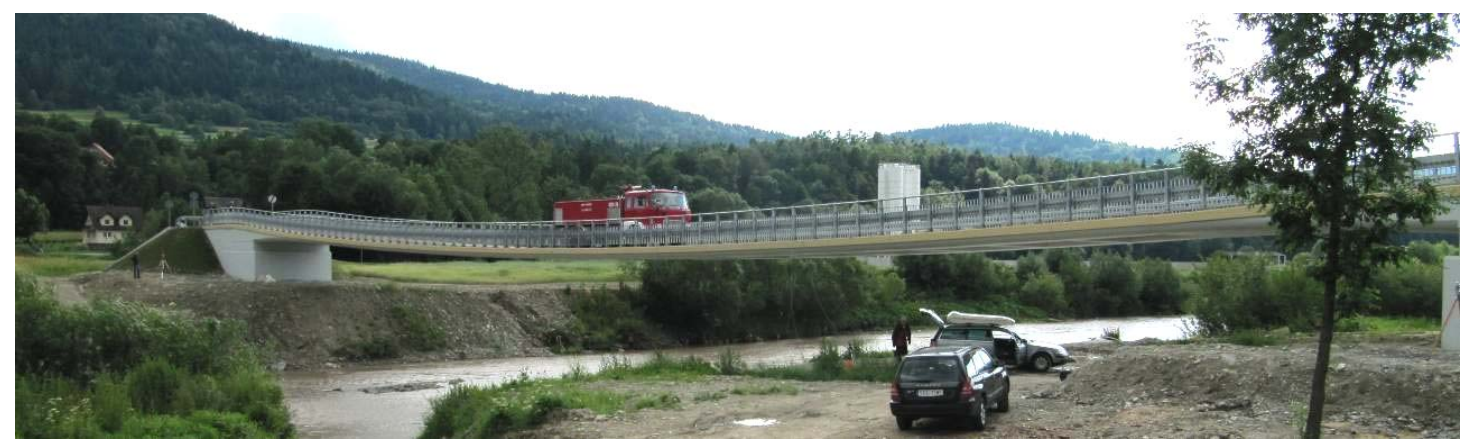

Fig. 915 tons car driving with $30 \mathrm{~km} / \mathrm{h}$ speed during load test.

experience of designing and erecting such structures. It is a very valuable experience because a new, even more complicated structures are already in the final stages of design [10]. It was confirmed that they can be successfully applied in construction of light crossings like footbridges or small road bridges reaching high structure durability, aesthetical view and low costs. This kind of structure has also a few important advantages to be mentioned. First of all, short erection time thanks to using precast elements and assembly without frameworks by hanging to main cables. It allows erection over difficult terrain obstacles. Besides, high stiffness and long working life was gained thanks to applying high strength concrete and deck stressing by tendons with cement injection. The results of load test confirmed that the bridge has good dynamic resistance and greater stiffness than assumed in the design (Fig. 9).

\section{References}

[1] B. Markocki, S. Makar, G. Prokop, The Basic and Final Design of Stress Ribbon Bridge in Lubień, DHV Poland, Warszawa, 2012.

[2] B. Markocki, S. Makar, The Guideline of Cable Stressing of Stress Ribbon Bridge in Lubień, DHV Poland, Warszawa, 2012.

[3] H. Bachmann, W. Ammann, Vibrations Problems in
Structures, Birkhauser Verlag, Basel, 1997.

[4] C. Seiler, S. Huttner, A uniform model for pedestrian induced loads for different types of motion: Theory, experimental tests and practical application, in: Proceedings of the 6th European Conference on Structural Dynamics, Paris, France, Sep. 4-7, 2005, pp. 1655-1660.

[5] M. Salamak, P. Łaziński, Experimental identification of the dynamic properties of three different footbridge structures, in: 3rd International Conference on Footbridge, Porto, July 2-4, 2008, pp. 319-320.

[6] P. Kuras, T. Owerko, L. Ortyl, R. Kocierz, O. Skuta, S. Pradelok, Advantages of radar interferometry for assessment of dynamic deformation of bridge, in: Proceedings of the Sixth International IABMAS Conference, Stresa, Lake Maggiore, Italy, July 8-12, 2012, pp. 885-891.

[7] T. Owerko, Ł. Ortyl, R. Kocierz, P. Kuras, M. Salamak, Investigation of displacements of road bridges under test loads using radar interferometry-Case study, in: Proceedings of the Sixth International IABMAS Conference, Stresa, Lake Maggiore, Italy, July 8-12, 2012, pp. 181-188.

[8] C. Butz, A. Cunha, E. Caetano, F. Magalhaes, A. Goldack, Experimental characterisation of the dynamic behaviour of lively footbridges, in: 2nd International Conference on Footbridge, Venice, Dec. 6-8, 2005.

[9] J. Strasky, Stress Ribbon and Cable Supported Pedestrian Bridges, Thomas Telford Ltd., London, 2005.

[10] M. Salamak, Suspension footbridge with slender concrete deck over the san in Sanok, in: 3rd International Conference on Footbridge, Porto, July 2-4, 2008, pp. 173-174. 